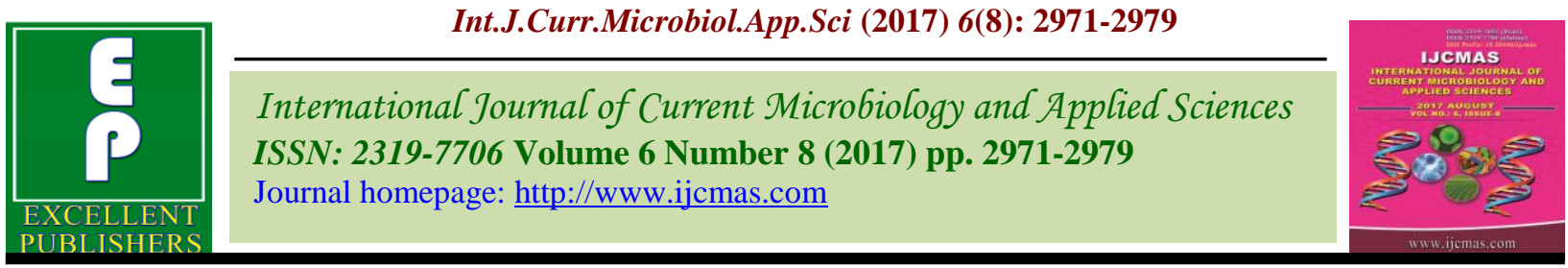

Original Research Article

https://doi.org/10.20546/ijcmas.2017.608.356

\title{
Carpogenic Germination and Viability Studies of Sclerotia of Sclerotinia sclerotiorum Causing Lettuce Drop
}

\author{
Meenu Gupta* and Kirtipal Singh \\ Department of Vegetable Science, Dr YS Parmar University of Horticulture and Forestry, \\ Nauni, Solan HP-173230- India \\ *Corresponding author
}

A B S T R A C T

Keywords

Carpogenic germination, Sclerotinia sclerotiorum, Lactuca sativa, Lettuce drop, Viability studies.

Article Info

Accepted:

23 June 2017

Available Online:

10 August 2017

Lettuce is one of the most widely consumed vegetable throughout the world. Amongst various diseases infecting this crop, lettuce drop caused by Sclerotinia sclerotiorum is one of the most prominent and destructive one. Lettuce drop pathogen, S. sclerotiorum produces black, hard survival structures known as sclerotia. In the present studies, carpogenic germination of sclerotia by producing apothecia and releasing ascospores as well as viability of sclerotia was studied. Sclerotia after germination formed funnel shaped cup i.e. apothecium at the tip which were brown in color and were round or globose type. The length of apothecia varied from 4-19 mm, whereas diameter of the apothecial discs ranged from 3-8 $\mathrm{mm}$ with number ranging from 1-10 per sclerotia. Viability studies revealed that with the increase in duration of water soaking from 4 days to 32 days, there was a gradual decrease in germination of sclerotia of S. sclerotiorum. $20^{\circ} \mathrm{C}$ temperature was found to be optimum resulting in maximum sclerotial germination $(99.73 \%)$ followed by $25,15,10$ and $30^{\circ} \mathrm{C}$ temperature. Soil depth $(0$ to $12 \mathrm{~cm})$ was inversely proportional to sclerotial germination and sclerotia placed at soil surface $(0 \mathrm{~cm}$ soil depth) resulted in highest sclerotial germination ( $93.75 \%$ ) followed by 2,4 and $6 \mathrm{~cm}$ soil depths.

\section{Introduction}

Lettuce (Lactuca sativa L.) is one of the most widely consumed vegetables around the world. It is often grown as a biennial leafy vegetable and is typically eaten raw in salads, sandwiches and in many other ethnic dishes. Its tender leaves and head are chopped and used as salad with salt and vinegar. In India, it is gaining popularity with the change in food habit and health consciousness among the people (Kaushal and Kumar, 2010).During its cultivation, lettuce drop caused by Sclerotinia sclerotiorum has been found to be predominant and destructive disease (Bharat et al., 2014). It produces hard, durable structures known as sclerotia, which function as survival structures and also as disease inoculum in subsequent lettuce crops. Sclerotia of S. sclerotiorum usually germinate erruptively resulting in symptoms development; however, they can also germinate carpogenically producing numerous apothecia that forcibly eject thousands of ascospores to be wind-dispersed throughout the lettuce field and adjacent production areas (Subbarao, 1998). The result of ascospore-mediated lettuce drop is often complete loss of crop at the primary infection site and considerable damage to surrounding lettuce fields. However, much information is not available regarding its carpogenic 
germination and viability studies, therefore, present investigations were undertaken.

\section{Materials and Methods}

\section{Production of sclerotia}

Wheat seeds $(25 \mathrm{~g})$ were placed in $250 \mathrm{ml}$ flasks containing $60 \mathrm{ml}$ water and autoclaved. After cooling, each flask was inoculated with three mycelial discs (10 $\mathrm{mm}$ diameter) taken from the colony margin of 3-4 day old PDA cultures of $S$. Sclerotiorum, isolated from infected lettuce leaves. Flasks were incubated at $20^{\circ} \mathrm{C}$ for 3 weeks in darkness, with each flask being shaken after 1 week to facilitate mixing of inoculum (Plate 1a). After 3 weeks, the contents of each flask were washed with sterile distilled water in a sieve $(1 \mathrm{~mm}$ diameter pore size) and aseptically air-dried overnight in a laminar flow hood (Plate 1b). Sclerotia were separated from the wheat grains, stored at room temperature in the dark (Plate 1c) and used within 2 weeks (Mylchreest and Wheeler, 1987).

\section{Carpogenic germination of sclerotia}

To record the carpogenic germination of sclerotia in moist sand in Petri plates, clean sand was sterilized for one hour in autoclave at $1.05 \mathrm{~kg} / \mathrm{cm}^{2}$ for two consecutive days. Sixty gram of sterilized sand was spread in each Petri plate $(9 \mathrm{~cm}$ dia.). Five sclerotia per Petri plate were buried in sand and moistened with sterilized distilled water regularly and kept for carpogenic germination at room temperature $\left(10+5^{0} \mathrm{C}\right)$ and observations on formation of apothecia were recorded regularly.

\section{Effect of different durations of water dipping on viability of sclerotia}

Effect of different durations of water dipping i.e. $4,8,12,16,20,24,28,32$ days on viability of sclerotia was studied by soaking sclerotia in water for different durations (Plate
2) and then plating them on PDA plates and observation on sclerotial germination $(\%)$ was recorded up to five days.

\section{Effect of different temperature regimes on viability of sclerotia}

Germination of sclerotia was studied by maintaining different temperature levels i.e. 0 , $5,10,15,20,25,30,35$ and $40^{\circ} \mathrm{C}$ for four weeks in BOD incubator (Plate 3) and then plating them on PDA plates. Observations on sclerotial germination $(\%)$ were recorded up to thirty days at an interval of ten days each.

\section{Effect of different soil depths on viability of sclerotia}

Different soil depths i.e. 0, 2, 4, 6, 8, 10 and $12 \mathrm{~cm}$ on germination of sclerotia was studied by burying the sclerotia in nylon bags at different soil depths (Plate 4) for four weeks and then plating them on PDA plates. Observations on sclerotial germination (\%) were recorded at ten days interval up to one month.

\section{Results and Discussion}

\section{Formation of sclerotia and their carpogenic germination}

Small, round or oval to irregular in shape, transparent bodies started developing after 8-9 days of incubation and these later turned black in color and became hardened sclerotia of the fungus (Plate 5a,5b and 5c). The sclerotia were round to irregular in shape in culture and measured $1.6-8 \mathrm{~mm}$ in width and 2.1-17 $\mathrm{mm}$ in length and their number varied from 20-30 per Petri plate.

Singh (1985) found that sclerotia varied in shape and size according to environment and location. Saharan and Mehta (2008) reported that sclerotium formation in S. sclerotiorum follows a general sequence but variations due 
to isolates, substrates and conditions exist. Later, Bharat et al., (2014) confirmed sclerotia to be black in colour, smooth, rounded or elongated and 1-6 x 1-20 mm in size.

The sclerotial germination gave rise to several columnar structures (stipes) which later formed funnel shaped cup (apothecium) at the tip (Plate 6). Apothecia were brown in color and were round or globose type. The length of apothecia measured from 4-19 $\mathrm{mm}$, whereas diameter of the apothecial discs ranged from 3-8 $\mathrm{mm}$ with number ranging from 1-10 per sclerotia. Eddins (1937) reported that apothecial cups were $1.5-10 \mathrm{~mm}$ in diameter.

Apothecial production from stipes produced on sclerotia placed on a substrate low in nutrients under proper conditions have been reported by Saito (1973) and Steadman and Nickerson (1975).

\section{Effect of different durations of water dipping on viability of sclerotia}

It is evident from the data (Table 1) that with the increase in duration of water soaking from 4 days to 32 days, there was a gradual decrease in germination of sclerotia of $S$. sclerotiorum from 88.66 to 8.65 per cent, respectively, though all treatments were statistically different from each other. Thus, soaking of sclerotia in water reduced its viability.

Moore (1949) indicated that the survival of sclerotia of $S$. sclerotiorum under flooded conditions ranged between 23 and 45 days.

As a result, flooding has been used for control of diseases caused by Sclerotinia on a number of crops in Florida (Moore, 1949; Steadman, 1979) and in western Washington (Niem et al., 2013). Increasing soil moisture accelerates sclerotium degradation (ColeySmith and Cooke, 1971) and also increases their susceptibility to damage from solar radiation (Willetts and Wong, 1980). Metha (2014) reported that moist sclerotia die rapidly than the dried ones.

It is concluded from the data in table 1 that soaking of sclerotia in water for about one month hampers its viability.

\section{Effect of different temperature regimes on viability of sclerotia}

The perusal of data (Table 2) revealed that sclerotia of $S$. sclerotiorum were able to germinate at all the temperatures ranging from 0 to $40^{\circ} \mathrm{C}$, however, $20^{\circ} \mathrm{C}$ temperature was found to be optimum resulting in maximum sclerotial germination $(99.73 \%)$ followed by $25,15,10$ and $30^{\circ} \mathrm{C}$ temperature giving $96.95,94.67,81.70$ and 76.13 per cent sclerotial germination, though statistically at par with each other. Minimum sclerotial germination was observed at $40^{\circ} \mathrm{C}$ temperature.

Data further suggested that a decreasing trend in sclerotial germination, irrespective of the temperature, was observed after 10 days to 30 days. It was highest after 10 days (68.33\%) followed by 20 days (64.44\%) and 30 days $(59.56 \%)$, though statistically similar to each other.

Interaction studies showed that minimum sclerotial germination was found at $40^{\circ} \mathrm{C}$ temperature after 30 days of temperature exposure $(4.59 \%)$, whereas, highest sclerotial germination was observed at $20^{\circ} \mathrm{C}$ temperature after 10 and 20 days of exposure.

Singh (1985) observed that sclerotia of $S$. sclerotiorum were able to germinate at 40,50 and $60^{\circ} \mathrm{C}$ even after 24 hours of exposure, however, at $70^{\circ} \mathrm{C}$, exposure for longer periods inhibited germination while the sclerotial germination occurred when exposed for 2 hours only. 
Table.1 Effect of different durations of water dippings on sclerotial germination of S. sclerotiorum

\begin{tabular}{cc}
\hline Days of water dipping & Sclerotial germination $(\%)$ \\
\hline $\mathbf{4}$ & $88.66(70.34)$ \\
$\mathbf{8}$ & $62.04(51.95)$ \\
$\mathbf{1 2}$ & $56.67(48.81)$ \\
$\mathbf{1 6}$ & $44.48(41.81)$ \\
$\mathbf{2 0}$ & $31.88(34.35)$ \\
$\mathbf{2 4}$ & $22.32(28.16)$ \\
$\mathbf{2 8}$ & $12.45(20.61)$ \\
$\mathbf{3 2}$ & $8.65(17.02)$ \\
$\mathbf{C D}(\mathbf{0 . 0 5})$ & $(2.61)$ \\
\hline
\end{tabular}

Figures in the parenthesis are arc sine transformed values

Table.2 Effect of different temperature regimes on sclerotial germination of S. sclerotiorum

\begin{tabular}{ccccc}
\hline Temperature $\left({ }^{\mathbf{0}} \mathbf{C}\right)$ & \multicolumn{3}{c}{ Sclerotial germination (\%) } \\
& After 10 days & After 20 days & After 30 days & Mean \\
\hline $\mathbf{0}$ & $40.42(39.25)$ & $34.54(35.99)$ & $28.72(32.83)$ & $34.56(36.02)$ \\
$\mathbf{5}$ & $65.58(53.78)$ & $59.24(50.20)$ & $53.82(47.08)$ & $59.54(50.35)$ \\
$\mathbf{1 0}$ & $86.24(68.37)$ & $81.39(64.73)$ & $77.48(61.71)$ & $81.70(64.94)$ \\
$\mathbf{1 5}$ & $98.24(82.15)$ & $95.34(79.66)$ & $90.43(72.43)$ & $94.67(78.08)$ \\
$\mathbf{2 0}$ & $100.00(90.00)$ & $100.00(90.00)$ & $99.19(85.59)$ & $99.73(88.53)$ \\
$\mathbf{2 5}$ & $98.24(83.86)$ & $96.89(79.25)$ & $95.73(79.96)$ & $96.95(81.02)$ \\
$\mathbf{3 0}$ & $82.75(65.27)$ & $75.73(60.40)$ & $69.91(56.54)$ & $76.13(60.74)$ \\
$\mathbf{3 5}$ & $34.46(35.94)$ & $28.46(32.45)$ & $16.18(23.91)$ & $26.36(30.74)$ \\
$\mathbf{4 0}$ & $09.08(17.77)$ & $08.44(16.29)$ & $04.59(12.17)$ & $07.37(15.41)$ \\
Mean & $68.33(59.60)$ & $64.44(56.55)$ & $59.56(52.47)$ & \\
CD( $\left.\mathbf{0 . 0 5}_{\mathbf{0 . 0}}\right)$ & & & & \\
Temp & & 33.21 & & \\
Days & & 19.18 & & \\
Temp x days & & 57.54 & & \\
\hline
\end{tabular}

Figures in the parenthesis are arc sine transformed values

Table.3 Effect of different soil depths on sclerotial germination of S. sclerotiorum

\begin{tabular}{|c|c|c|c|c|}
\hline \multirow{2}{*}{ Soil depth (cm) } & \multicolumn{4}{|c|}{ Sclerotial germination (\%) after days } \\
\hline & 10 & 20 & 30 & Mean \\
\hline $\mathbf{0}$ & $98.00(83.42)$ & $97.22(63.42)$ & $86.04(39.21)$ & $93.75(62.01)$ \\
\hline 2 & $97.52(80.42)$ & $90.85(61.33)$ & $83.87(51.92)$ & $90.74(64.55)$ \\
\hline 4 & $87.63(68.03)$ & $80.06(65.64)$ & $77.63(44.40)$ & $81.77(59.35)$ \\
\hline 6 & $83.07(80.42)$ & $71.22(57.40)$ & $51.35(35.64)$ & $68.54(57.82)$ \\
\hline 8 & $73.85(71.59)$ & $63.54(45.36)$ & $40.34(46.70)$ & $59.24(54.55)$ \\
\hline 10 & $62.04(65.64)$ & $49.04(58.68)$ & $34.19(38.62)$ & $48.42(54.31)$ \\
\hline 12 & $53.10(68.87)$ & $39.09(52.51)$ & $27.28(31.28)$ & $39.82(50.88)$ \\
\hline Mean & $79.31(74.05)$ & $70.14(57.76)$ & $57.24(41.11)$ & \\
\hline \multicolumn{5}{|l|}{$\mathrm{CD}\left({ }_{0.05}\right)$} \\
\hline Soil depth & \multicolumn{4}{|c|}{33.23} \\
\hline days & \multicolumn{4}{|c|}{21.75} \\
\hline Soil depth $x$ days & \multicolumn{4}{|c|}{57.56} \\
\hline
\end{tabular}

Figures in the parenthesis are arc sine transformed values 
Plate.1a Inoculated wheat seeds after incubating at $20^{\circ} \mathrm{C}$ for 3 weeks in darkness

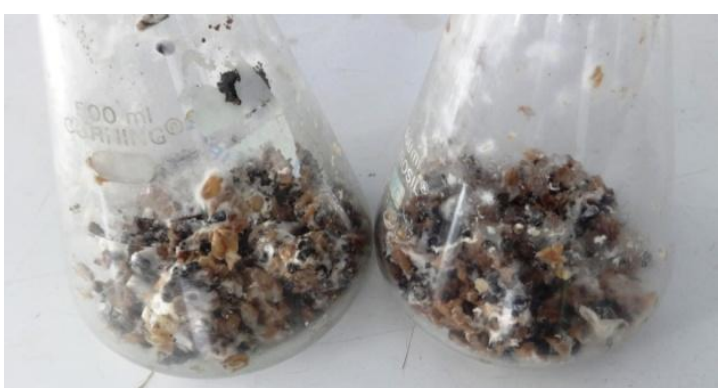

Plate.1b Harvesting of sclerotia

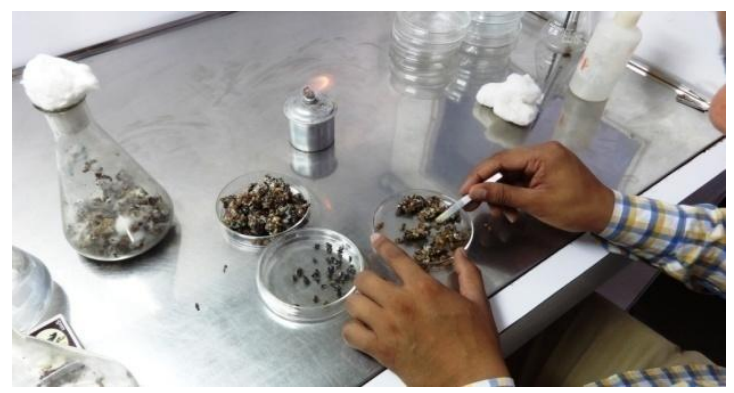

Plate.1c Harvested sclerotia for further use

Plate.2 Water dipping of sclerotia

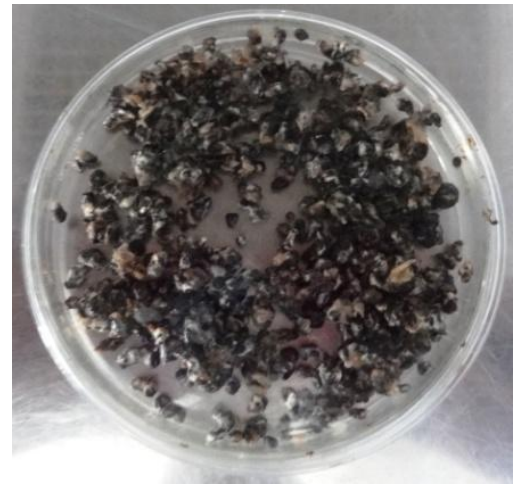

Plate.3 Sclerotia exposed to different temperatures
Plate.4 Burial of sclerotia at different soil depths
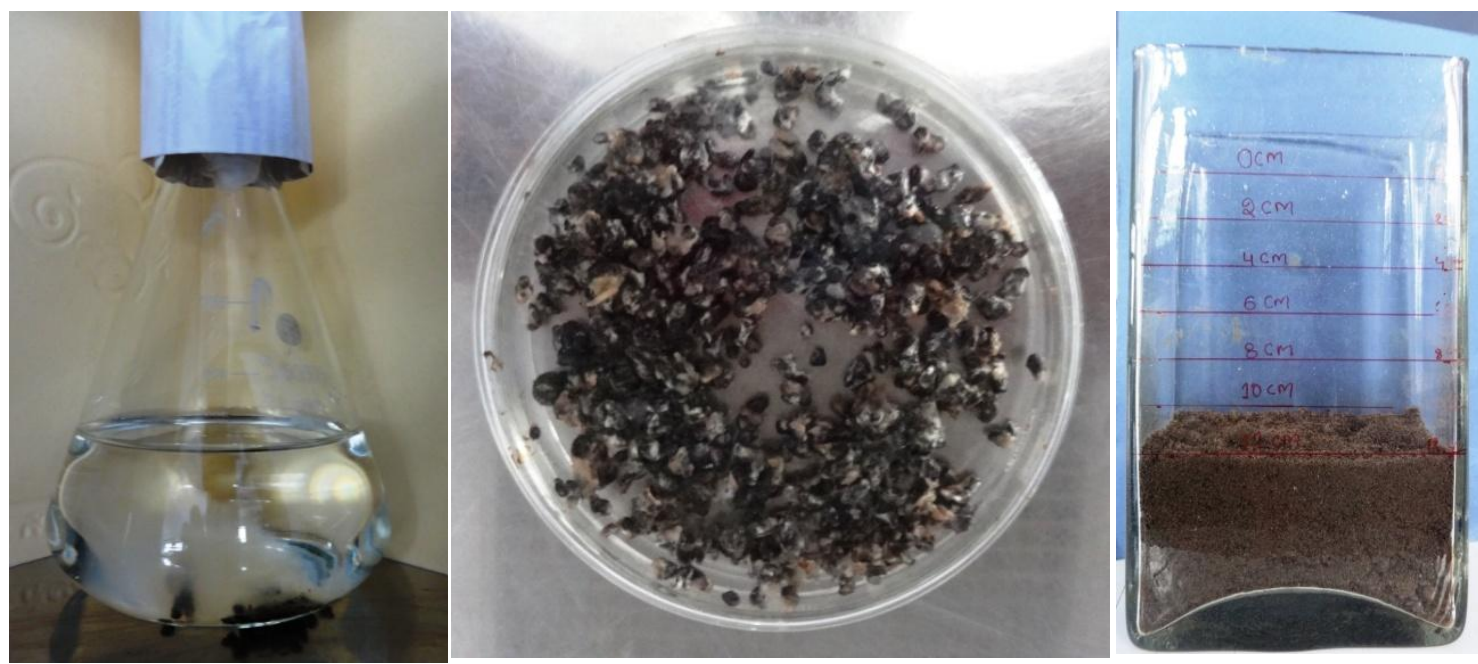

Plate.5a Sclerotia of $S$. sclerotiorum
produced on PDA

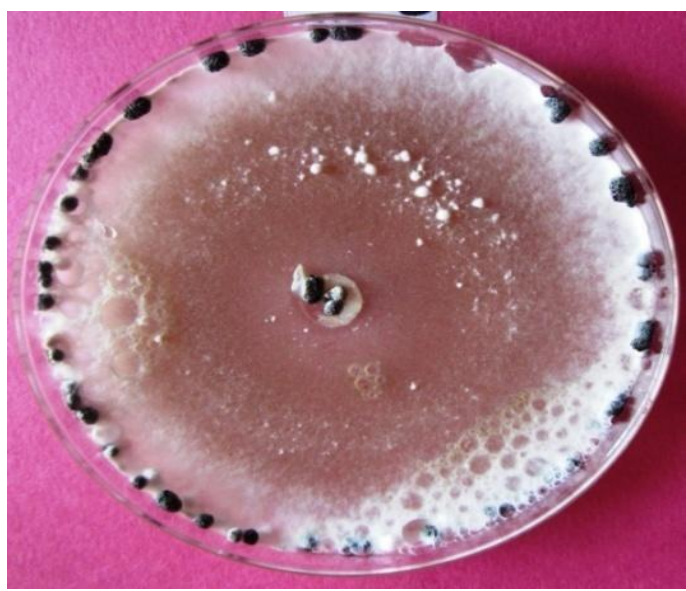

Plate.5c Cross section of sclerotia of $S$. sclerotiorum

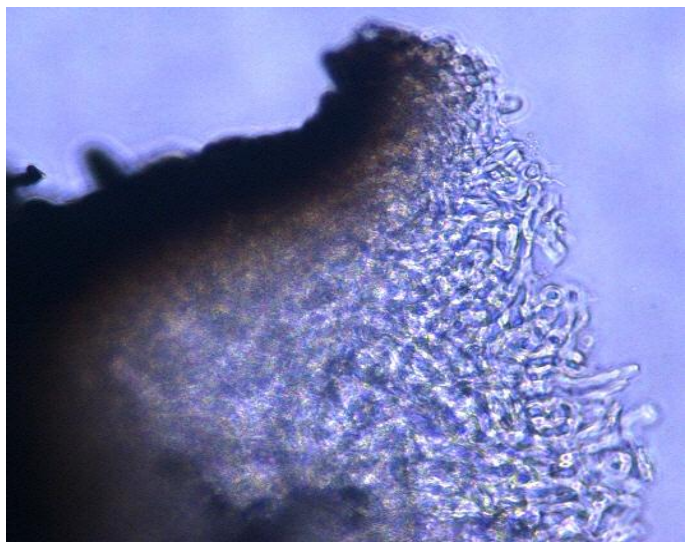

Cartia and Asero (1994) reported that 40 per cent mortality of sclerotia of $S$. sclerotiorum was obtained at a temperature of $35^{\circ} \mathrm{C}$ after three days while 100 per cent mortality was achieved after nine-ten days of exposure.

Abdullah et al., (2008) found that sclerotia did not grow after 7 days at 30 and $35^{\circ} \mathrm{C}$, however, when these sclerotia were incubated at $25^{\circ} \mathrm{C}$, normal myceliogenic growth resumed. Sclerotia that were exposed to 40 and $45^{\circ} \mathrm{C}$ failed to grow after 21 days at $25^{\circ} \mathrm{C}$. The upper thresholds temperature for
Plate.5b Sclerotia of lettuce drop pathogen

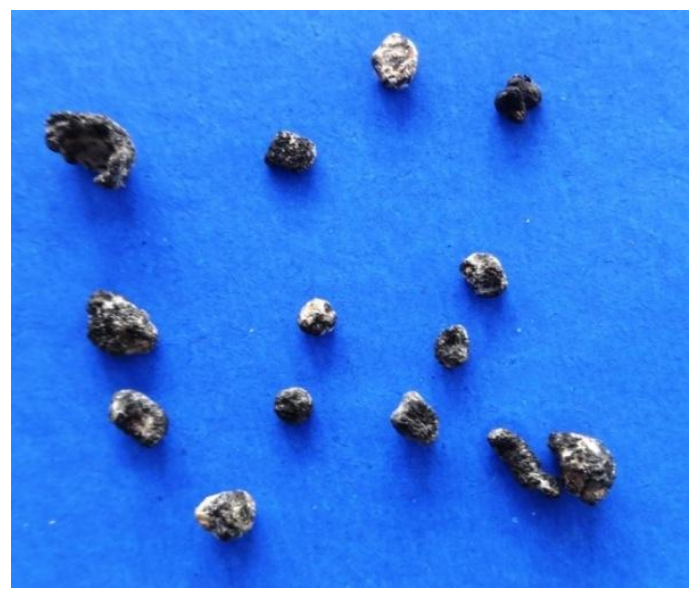

Plate.6 Apothecia of S. sclerotiorum

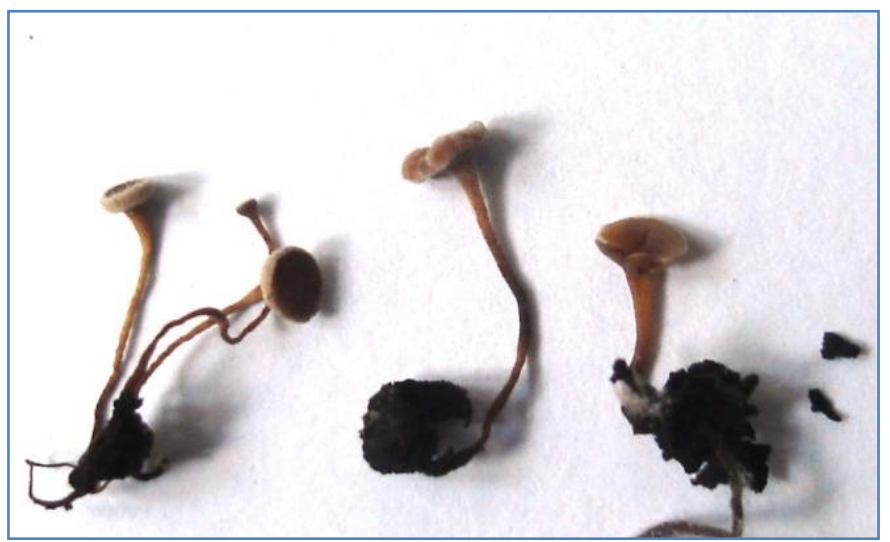

conditioning and germination of sclerotia were 20 and $25^{\circ} \mathrm{C}$, respectively (Clarkson et al., 2007). The sclerotial germination of $S$. sclerotiorum tended to decrease as soil temperature increased from 15 to $40^{\circ} \mathrm{C}$, with no germination observed at $40^{\circ} \mathrm{C}$ after 1 and 2 weeks, respectively (Matheron and Porchas, 2005).

It can be concluded from the present experiment (Table 2) that a temperature range of 10 to $30^{\circ} \mathrm{C}$ supports higher sclerotial germination. 


\section{Effect of different soil depths on viability of sclerotia}

Result presented in table 3 showed that with the increase in soil depth from 0 to $12 \mathrm{~cm}$, there was a corresponding decrease in sclerotial germination, irrespective of days of burial in soil. Sclerotia placed at soil surface $(0 \mathrm{~cm}$ soil depth) resulted in highest number of sclerotial germination $(93.75 \%)$ followed by 2,4 and $6 \mathrm{~cm}$ soil depth giving 90.74 , 81.77 and 68.54 per cent germination of sclerotia, respectively. Data further showed that sclerotial burial in soil for 10,20 and 30 days, irrespective of soil depth did not differ significantly among each other, however, 10 days of burial of sclerotia in soil gave highest percentage of sclerotial germination $(79.31 \%)$.

It was found from interaction studies that highest percentage of sclerotial germination was observed at soil surface $(0 \mathrm{~cm}$ soil depth) after 10 days of burial in soil $(98.00 \%)$. This was followed by burying the sclerotia at $2 \mathrm{~cm}$ soil depth up to 10 days giving 97.52 percent sclerotial germination, though statistically similar to each other.

Viability of sclerotia of Sclerotinia spp. in soil has been reported to be as short as a few weeks to as long as 8 years or more (Moore, 1949) and it is difficult to measure in the field even in the absence of susceptible hosts because the "primary" sclerotia produce "secondary" or "daughter" sclerotia in the absence of suitable substrates for colonization (Adams and Ayers, 1979; Coley-Smith and Cooke, 1971). This not only causes an increase in the number of sclerotia, but it also extends their viability (Coley-Smith and Cooke, 1971; Kruger, 1975; Willetts and Wong, 1980). Imolehinet al., (1980) reported that the increased mortality of sclerotia at deeper soil is mainly due to the colonization of sclerotia by antagonistic fungi. Merriman
(1976) reported that burial of sclerotia at $4 \mathrm{~cm}$ for 35 weeks reduced recovery of sclerotia to zero in sandy clay loam and by 50 percent in sandy loam. Because survival of sclerotia decreases with time and depth of burial, movement of sclerotia to depths greater than $10 \mathrm{~cm}$ will prevent lettuce drop infections (Grogan et al., 1980 and Imolehin and Grogan, 1980). Factors such as soil temperature, $\mathrm{O}_{2}, \quad \mathrm{CO}_{2}, \quad$ and ethylene concentrations change with soil depth and may influence survival ( $\mathrm{Wu}$ and Subbarao, 2008).

It can be inferred from the data in table 3 that sclerotial germination was inversely proportional to soil depth and duration of burial in soil and with the increase in soil depth as well as duration of burial, there was a decrease in sclerotial germination.

\section{References}

Abdullah, M.T., Ali, N.Y. and Suleman, P. 2008. Biological control of Sclerotinia sclerotiorum (Lib.) de bary with Trichoderma harzianum and Bacillus amyloliquefaciens. Crop Protec., 27: 1354-1359.

Adams, P.B., and Ayers, W.A. 1979. Ecology of Sclerotinia species. Phytopathology, 69(8):896-899.

Bharat, N.K., Thakur, M., Bhardwaj, R.K. and Kumar, S. 2014. Occurrence of Sclerotinia rot and Botrytis gray mould on lettuce under protected conditions in Himachal Pradesh. International Journal of Farm Sciences, 4(2): 86-91.

Brooks, A.N., 1942. Control of celery pink rot. Florida Agric. Exp. Stat. Bull., p 567.

Cartia G., and Aseri C. 1994.The role of temperature regarding Sclerotinia sclerotiorum in the soil solarization method. ActaHorticulturae366: 323330. 
Clarkson, J.P., Phelps, K., Whipps, M.J., Young, C.S., Smith, A.J. and Watling, M. 2007. Forecasting sclerotinia disease on lettuce: a predictive model for carpogenic germination of Sclerotinia sclerotiorum sclerotia. Phytopathology, 97(5): 621-631.

Coe D M., 1944. Variations in single ascospore isolates of Sclerotinia sclerotiorum. Mycologia36: 235-241.

Coley-Smith, J.R., and Cooke, R.C. 1971.Survival and germination of fungal sclerotia. Annual Review of Phytopathology, 9: 65-92.

Eddins, A. H., 1937. Sclerotinia rot of Irish potatoes. Phytopathology, 37(1): 100103.

Grogan, R.G., Sall, M.A. and Punja, Z.K. 1980. Concepts for modeling root infection by soilborne fungi. Phytopathology, 70(5): 361-363.

Humpherson-Jones, F.M. and Cooke, R.C. 1977.Morphogenesis in sclerotium forming fungi II. Rhythmic production of sclerotia by Sclerotinia sclerotiorum (Lib.) de Bary. New Phytopathology, 78: 181-187.

Imolehin E D and Grogan R G. 1980.Effects of oxygen, carbon dioxide, and ethylene on growth, sclerotial production, germination and infection by Sclerotinia minor.Phytopathology,70: 1158-1161.

Imolehin, E.D., Grogan, R.G. and Duniway, J.M. 1980. Effect of temperature and moisture tension on growth, sclerotial production, germination, and infection by Sclerotinia minor. Phytopathology, 70(12): 1153-1157.

Kaushal, S., and Kumar, R. 2010. Genetic divergence studies in newly introduced genotype of lettuce (Lactuca sativa L.) African J. Basic Appl. Sci., 2(1-2): 1824.

Kruger, W., 1975. Influence of weather on the attack of rape by Sclerotinia sclerotiorum Lib.) de Bary.
Nachrichtenble Devet $P$ flanzenschutzd (Braunschweig), 27: 1-6.

Matheron, M.E., and Porchas, M. 2005. Influence of soil temperature and moisture on eruptive germination and viability of sclerotia of Sclerotinia minor and S. sclerotiorum. PlantDis, 89: $50-54$.

Mehta, N., Hieu, N.T. and Sangwan, M.S. 2012. Efficacy of various antagonistic isolates andspecies of Trichoderma against Sclerotinia sclerotiorum causing white stem rot of mustard. J. Mycol. Pl.Pathol., 42: 244-250.

Merriman, P.R., 1976. Survival of sclerotia of Sclerotinia sclerotiorumin soil. Soil Biology and Biochemistry, 8: 385-389.

Mehta, N., 2014. Epidemiology and forecasting for the management of rapeseed-mustard diseases. Journal of Mycology and Plant Pathology, 44(2): 131-147.

Moore, W.D., 1949. Flooding as a means of destroying sclerotia of Sclerotinia sclerotiorum. Phytopathology, 39: 920927.

Mylchreest, S.J., and Wheeler, B.E.J. 1987. A method for inducing apothecia from sclerotia of Sclerotinia sclerotiorum. Plant Pathol, 36: 16-20.

Niem, V.D.J., Gundersen, B. and Inglis, D.A. 2013. Effects of soil flooding on the survival oftwo potato pathogens Sclerotinia sclerotiorum and S. minor. American J. PotatoRes., 90: 578-590.

Purdy, L.H., 1955. A broader concept of the species Sclerotinia sclerotiorum based onvariability. Phytopathology, 45: 421427.

Saharan, G.S., and Mehta, N. 2008.Sclerotinia Diseases of Crop Plants: Biology, Ecology andDisease Management, Springer Science, p 485.

Saito I., 1973. Initiation and development of apothecial stipe primodia in sclerotia of Sclerotinia sclerotiorum. Trans. Mycol. 
Soc. Japan, 14: 343-351.

Singh, R.S., 1985. Diseases of Vegetable Crops. Oxford and IBH Publishing Coperator, NewDelhi, pp 112-136.

Steadman, J.R., and Nickerson, K.W. 1975. Differential inhibition of sclerotial germination in Whetzelinia sclerotiorum. Mycopathologia, 57: 165170.

Steadman, J.R., 1979. Control of plant diseases caused by Sclerotinia species .Phytopathology, 69: 904-907.

Subbarao, K.V., 1998. Progress toward integrated management of lettuce drop. Plant Dis., 82: 1068-1078.
Trevethick, J., and Cooke, R.C. 1973. Water relations in sclerotia of some Sclerotinia and Sclerotium species. Trans. British Mycol. Soc., 60: 555-558.

Willetts, H.J., and Wong, J.A.L. 1980. The biology of Sclerotinia sclerotiorum, $S$. trifoliorum and $S$. minor with emphasis on specific nomenclature. Botanic. Rev., 46:101-165.

Wu, B.M., and Subbarao, K.V. 2008. Effects of soil temperature, moisture, and burial depths oncarpogenic germination of Sclerotinia sclerotiorum and S. minor. Phytopathology, 98:1144-1152.

\section{How to cite this article:}

Meenu Gupta and Kirtipal Singh. 2017. Carpogenic Germination and Viability Studies of Sclerotia of Sclerotinia sclerotiorum Causing Lettuce Drop. Int.J.Curr.Microbiol.App.Sci. 6(8): 2971-2979. doi: https://doi.org/10.20546/ijcmas.2017.608.356 